\title{
Staurosporine inhibits phosphorylation of translational regulators linked to $\mathrm{mTOR}$
}

\author{
AR Tee ${ }^{\star, 1}$ and CG Proud ${ }^{1}$ \\ ${ }^{1}$ School of Life Sciences, Medical Sciences Institute/Wellcome Trust Building \\ Complex, University of Dundee, Dow Street, Dundee, DD1 5EH, UK \\ * Corresponding author: AR Tee, School of Life Sciences, Medical Sciences \\ Institute/Wellcome Trust Building Complex, University of Dundee, Dow Street, \\ Dundee, DD1 5EH, UK. Tel. (44) 1382 345758; Fax (44) 1382 322424; \\ E-mail: a.r.tee@dundee.ac.uk
}

Received 22.11.00 revised 16.2.01 accepted 8.3.01

Editor Y Kuchino

\begin{abstract}
Treatment of Swiss 3T3 cells with staurosporine resulted in dephosphorylation of two proteins which play key roles in regulating mRNA translation. This occurred before the execution of apoptosis, assessed by caspase-3 activity. These translation regulators are p70 56 kinase, which phosphorylates ribosomal protein $\mathrm{S} 6$, and eukaryotic initiation factor (elF) 4E binding protein 1 (4E-BP1), which both lie downstream of the mammalian target of rapamycin (mTOR). This resulted in decreased p70 S6 kinase activity, dephosphorylation of ribosomal protein $\mathrm{S} 6$, increased binding of $4 \mathrm{E}-$ BP1 to elF4E and a concomitant decrease in elF4F complexes. Our data show that staurosporine impairs $\mathrm{mTOR}$ signalling in vivo but that this not due to direct inhibition of $\mathrm{MTOR}$ or to inhibition of protein kinase $\mathrm{C}$. It is becoming clear that agents which cause apoptosis inactivate mTOR signalling as a common early response prior to the execution of apoptosis, i.e., before caspase activation. Cell Death and Differentiation (2001) 8, 841-849.
\end{abstract}

Keywords: mTOR; apoptosis; mRNA translation; staurosporine; PKC; initiation factor

Abbreviations: BIM, bisindolylmaleimide; elF, eukaryotic initiation factor; 4E-BP1, eukaryotic initiation factor 4E-binding protein 1; HEK 293, human embryonic kidney 293; MEK, MAP kinase/Erk kinase; $\mathrm{m}^{7}$ GTP, 7-methylguanosine triphosphate; mTOR, mammalian target of rapamycin; p70 S6 kinase, $70 \mathrm{kDa}$ protein kinase that phosphorylates ribosomal protein S6; PKC, protein kinase C; PKR, double-stranded RNA-dependent protein kinase; Z-VAD.FMK, ZVal-Ala-Asp.fluoromethylketone

\section{Introduction}

mRNA translation requires the concerted action of ribosomes, tRNAs and proteins termed translation factors. The control of protein synthesis involves changes in the phosphorylation of a number of translation factors, which alters their activities or their ability to interact with one another (reviewed $\mathrm{in}^{1,2}$ ).
Regulation of translation initiation is the main control point for mRNA translation. Several steps in translation are regulated by signalling events coupled to mTOR (mammalian target of rapamycin). mTOR regulates translation initiation through altering the phosphorylation state of proteins involved in mRNA translation. These include the protein kinase p70 S6 kinase, which phosphorylates S6, a component of the 40S subunit, and is thought to play an important role in regulating the translation of the subset of mRNAs which encode ribosomal proteins and certain translation factors. ${ }^{3,4}$ Activation of p70 S6 kinase is blocked by treatment of cells with rapamycin showing that activation of p70 S6 kinase is dependent on mTOR. Rapamycin also blocks the regulation of the eukaryotic initation factor 4E-binding protein 4E-BP1, which binds to elF4E, the protein which interacts with the 7methylguanosine cap at the $5^{\prime}$-end of the mRNA. ${ }^{5,6}$ elF4E also binds to elF4G leading to the formation of elF4F, the protein complex required for cap-dependent translation. Binding of 4E-BP1 to elF4E prevents elF4E from interacting with elF4G because the binding of both $4 \mathrm{E}-\mathrm{BP} 1$ and elF4G to elF4E is mutually exclusive. The binding of $4 \mathrm{E}-\mathrm{BP} 1$ to elF4E therefore inhibits the formation of elF4F complexes required for cap-dependent translation through a loss of elF4G association with elF4E. ${ }^{6}$

Translation initiation can also be regulated through the phosphorylation of the smallest $(\alpha)$ subunit of eukaryotic initiation factor 2 (elF2 $\alpha$ ). The guanine nucleotide-exchange factor elF2B catalyses recycling of the inactive GDP-bound form of elF2 to the active GTP-bound form, a rate limiting process for translation initiation. Phosphorylation of elF2 $\alpha$ on serine 51 results in inhibition of elF2B activity and therefore reduced recycling of elF2 to the active GTPform. ${ }^{7}$ Only the GTP-bound form of elF2 can bind methionyl-tRNA (Met-tRNA) and mediate its binding to the ribosome. Phosphorylation of elF2 $\alpha$ thus leads to inhibition of overall protein synthesis since inactive elF2.GDP complexes accumulate. Viral infection of mammalian cells can cause activation of the elF2 $\alpha$ kinase, PKR (doublestranded RNA-dependent protein kinase). Viral infection induces apoptosis which is dependent on PKR activation and elF2 $\alpha$ phosphorylation, indicating that the regulation of translation through elF $2 \alpha$ might be important during cell death. ${ }^{8-12}$

Recent studies have shown that inducers of apoptosis cause the inhibition of key regulatory components of translation. Commitment to the execution of apoptosis is characterised by the activation of the caspase cascade (reviewed $\mathrm{in}^{13}$ ). DNA-damaging agents inhibited mRNA translation even in the presence of the broad spectrum cellpermeable caspase inhibitor, Z-VAD.FMK, and prior to caspase activation. ${ }^{14,15}$ This indicates that such inhibition occurred during the pre-execution stage before the cells were committed to die and does not involve caspases. DNA damaging agents caused inhibition of p70 S6 kinase, 4E- 
BP1 phosphorylation and elF4F formation, all of which are linked to mTOR-signalling. This raises the possibility that inhibition of translation initiation may play a role in determining whether cells commit themselves to apoptosis.

The aim of this study was to determine whether another potent inducer of apoptosis, staurosporine, also inhibited mTOR-linked translation factors and whether this preceded, or occurred in parallel with, the execution stage of apoptosis. Here we demonstrate that staurosporine does indeed interfere with the regulation of such translation regulators and also brings about increased phosphorylation of another translation factor, elF2. These effects take place prior to the execution phase of apoptosis, i.e., before the caspase cascade is activated.

\section{Results}

\section{Staurosporine induces cell death in Swiss 3T3 cells independently of PKC inhibition}

Staurosporine induces apoptosis in a wide variety of cell types $^{16,17}$ and this is associated with caspase activation. To establish when apoptosis occurs in staurosporine-treated Swiss 3T3 cells, caspase- 3 activity was assessed in extracts treated for various times with staurosporine (Figure 1A). There was a marked rise in caspase-3 activity after $12 \mathrm{~h}$ of staurosporine treatment, indicating induction of apoptosis by this time. Caspase activity rose further by $18 \mathrm{~h}$. As expected, this induction of caspase activity was blocked by $20 \mu \mathrm{M} Z$ VAD.FMK. We have previously shown that 4E-BP1 is cleaved during apoptosis induced by DNA-damaging agents. ${ }^{14}$ It was therefore of interest to check whether 4E-BP1 was cleaved during apoptosis evoked by staurosporine. The cleaved product of 4E-BP1, indicated as the ' $\Delta$ ' species, was observed after $12 \mathrm{~h}$ of staurosporine-treatment (Figure 1B). The appearance of $\triangle 4 \mathrm{E}-\mathrm{BP} 1$ coincides with the rise in caspase-3 activity (Figure $1 \mathrm{~A}$ ) and was blocked by $\mathrm{Z}$ VAD.FMK indicating that 4E-BP1 cleavage was dependent on caspase activity.

Staurosporine is widely used as a protein kinase inhibitor, and was initially employed as an inhibitor of protein kinase $\mathrm{C}(\mathrm{PKC})$. Therefore, to establish whether the induction of apoptosis with staurosporine was due to its ability to inhibit PKC, we used bisindolylmaleimide-I (BIM), a broad range PKC inhibitor that inhibits the classical and non-classical PKC isoforms $(\alpha, \beta \mathrm{I}, \beta \mathrm{II}, \gamma, \delta, \varepsilon)$ to block PKC signalling. To verify that the concentration of BIM used was indeed sufficient to inhibit signalling through PKC, different concentrations of BIM were added to Swiss 3T3 cells and the cells were then treated with TPA to activate the classical and novel forms of PKC. A downstream target of PKC-signalling is the activation of MAP kinase (Erk). We therefore used an antibody specific for phosphorylated Erk1 and Erk2 to assess whether the concentration of BIM used blocked PKC signalling (Figure 1C). The data clearly show that $5 \mu \mathrm{M}$ BIM inhibits TPA-induced Erk activation, showing that, at this concentration, BIM effectively inhibits PKC activity. A possible alternative explanation for the effect of BIM on the activation of Erk is that it acts by inhibiting the upstream kinase which activates Erk, MEK (MAP kinase/
A

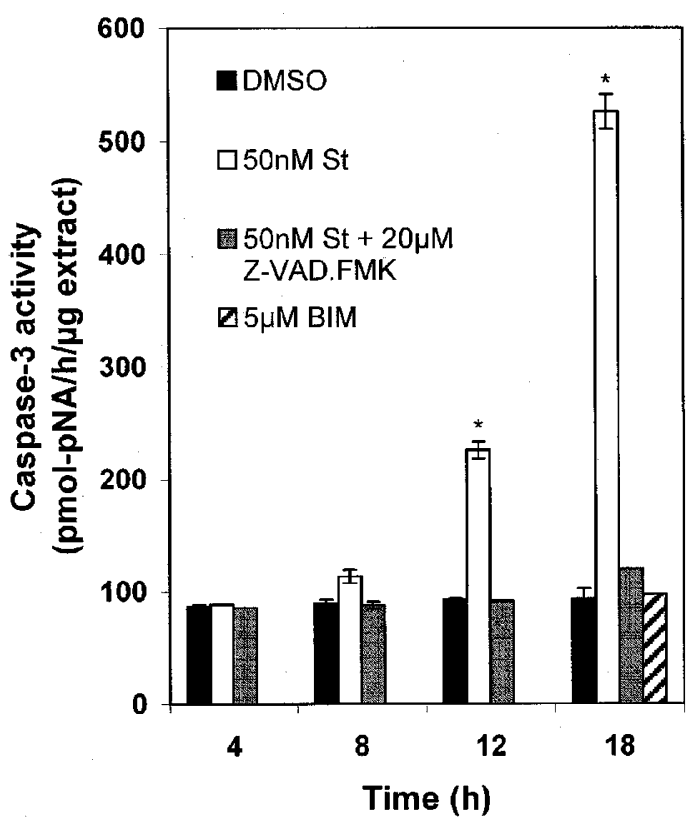

B
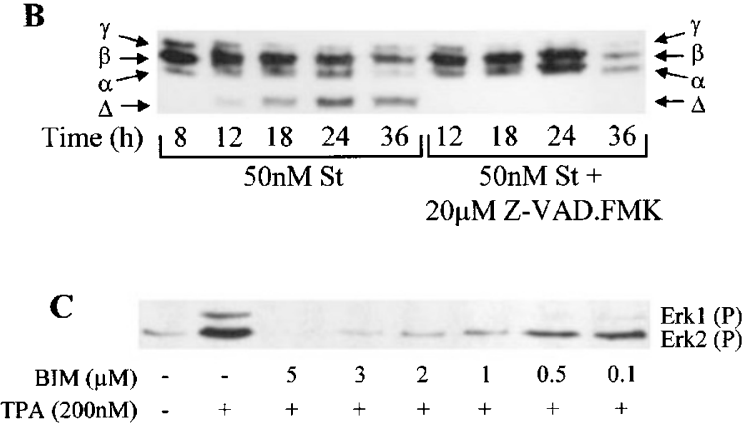

Figure 1 Staurosporine treatment induces apoptosis in Swiss 3T3 cells that is independent of PKC inhibition. (A) Swiss 3 T3 cells, where indicated, were treated with staurosporine (St) in the presence or absence of Z-VAD.FMK, bisindolylmaleimide (BIM) and caspase-3 activity assays were carried out as described in the Materials and Methods, $\left({ }^{*}=P<0.005\right.$ versus appropriate DMSO control, data show + S.D. $(n=3))$. (B) Swiss $3 T 3$ cells were treated at the times indicated with staurosporine $(50 \mathrm{nM} \mathrm{St})$, in the presence or absence of $20 \mu \mathrm{M}$ Z-VAD.FMK. The samples were subjected to SDS-PAGE and Western blot analysis to assess the phosphorylation state of 4E-BP1. The $\alpha, \beta$ and $\gamma$ of $4 \mathrm{E}-\mathrm{BP} 1$, and the cleavage product $\Delta$, are indicated by the arrows where the $\gamma$ species represents the most highly phosphorylated form of $4 \mathrm{E}$ BP1 and the $\Delta$ species represents the cleaved form of 4E-BP1. (C) Swiss 3T3 cells were pre-treated with or without $(-)$ a range of bisindolylmaleimide (BIM) concentrations, as indicated, for $30 \mathrm{~min}$, and then stimulated with TPA for $40 \mathrm{~min}$ before the cells were lysed and prepared for analysis. Samples from extracts ( $20 \mu \mathrm{g}$ of protein) were analyzed for Erk1 and Erk2 phosphorylation by Western blot analysis using antibodies that recognise phosphorylated Erk1 and Erk2. The positions of phospho-Erk1 and Erk2 are indicated

Erk kinase, MEK). However recent data show that, at the low micromolar concentrations used here, BIM has little effect on MEK while almost completely inhibiting PKC, ${ }^{18}$ apparently excluding this possibility. Treatment of cells with BIM did not evoke apoptosis, indicating that the inhibition of $\mathrm{PKC}$ alone is not enough to induce cell death. Thus the 
induction of apoptosis by staurosporine in Swiss 3T3 cells is independent of the inhibition of PKC. In line with our results, a series of BIM analogues did not induce apoptosis in HL-60 cells, while a closer structural analogue of staurosporine, Ro-31-8220, did induce apoptosis. ${ }^{19}$

\section{Staurosporine treatment leads to inhibition of translational regulators linked to $\mathrm{mTOR}$}

We have previously shown that the induction of apoptosis by DNA-damaging agents in Swiss 3T3 cells was preceded by inhibition of signalling through mTOR. ${ }^{14}$ It was therefore of interest to examine whether staurosporine, an agent which induces apoptosis by a different mechanism, also inhibited mTOR-dependent signalling. We therefore examined two proteins involved in regulating mRNA translation which lie downstream of mTOR. These are the p70 S6 kinase and 4EBP1. Both are regulated by phosphorylation in a manner which requires mTOR function, as demonstrated using the specific inhibitor of mTOR, rapamycin. ${ }^{4,6}$ Staurosporine caused a decrease in p70 S6 kinase activity within $1 \mathrm{~h}$ of treatment to almost the same extent as rapamycin treatment, while BIM caused no inhibition at any time studied (Figure 2A), showing that the effect of staurosporine on p70 S6 kinase is not linked to its ability to inhibit PKC. This effect occurs well before caspase activation (Figure $1 \mathrm{~A}$ ) and the cleavage of $4 \mathrm{E}$ BP1 (Figure 1B). Activation of p70 $S 6$ kinase is a consequence of its phosphorylation at multiple sites which causes a marked retardation of its mobility on SDS-PAGE. To assess whether the effect of staurosporine on p70 S6 kinase activity was a result of a change in its state of phosphorylation, SDS-PAGE/Western blot analysis of p70 S6 kinase was therefore carried out (Figure 2B). After $1 \mathrm{~h}$ of treatment with $50 \mathrm{nM}$ staurosporine, the slowest migrating (higher phosphorylated) band (marked ' $\mathrm{pp}$ ' in Figure 2B) disappeared and the intensity of the fastest migrating band increased showing that staurosporine treatment does indeed cause the dephosphorylation of p70 S6 kinase. As a positive control, rapamycin, which inhibits mTOR caused the disappearance of both the top (pp) and middle ( $p$ ) bands. However, BIM elicited no change in the phosphorylation state of p70 S6 kinase, assessed by its mobility on SDS-PAGE (data not shown). To verify that staurosporine did indeed inhibit p70 S6 kinase within Swiss 3T3 cells the degree of phosphorylation of ribosomal protein S6, a direct indicator of p70 S6 kinase activity in the cell, was monitored (Figure 2C). Treatment with either staurosporine or rapamycin caused a marked decrease in the phosphorylation of ribosomal protein S6, as detected with an antibody raised against a peptide corresponding to the phosphorylated form of S6. Dephosphorylation of ribosomal protein S6 was complete after $1 \mathrm{~h}$ of staurosporine-treatment in parellel with both the decreased activity (Figure 2A) and dephosphorylation (Figure 2B) of p70 S6 kinase.

4E-BP1 undergoes phosphorylation on at least five sites in vivo and, in its less phosphorylated forms, acts as an inhibitor of cap-dependent translation by binding to elF4E. The phosphorylation state of 4E-BP1 was assessed by subjecting cell extracts to Western blot analysis with anti4E-BP1 antibodies (Figure 2D). The most highly phos- phorylated species of 4E-BP1, labelled $\gamma$, migrates most slowly (uppermost band) while the least phosphorylated species, labelled $\alpha$, migrates as the fastest isoform (lowest band). There is a pronounced shift to the least phosphorylated isoform upon staurosporine treatment of Swiss 3T3 cells. This effect was evident as early as $1 \mathrm{~h}$, i.e., long before caspase activation and the execution phase of apoptosis. In contrast, no such substantial shift was observed with BIM, when compared to the DMSO vehicle control (Figure 2D): in both cases 4E-BP1 was mostly present in the hyperphosphorylated $\gamma$ form. The dephosphorylated species of $4 \mathrm{E}-\mathrm{BP} 1$ bind to and inhibit elF4E function by preventing the formation of elF4F complexes. We therefore examined whether staurosporine treatment resulted in decreased levels of elF4F complexes. elF4E was affinity purified by using chromatography on $m^{7}$ GTPSepharose and the relative levels of $4 \mathrm{E}-\mathrm{BP} 1$ and elF4G bound to elF4E were assessed by Western blotting analysis followed by densitometry (Figure $2 \mathrm{E}$ ). Staurospor-

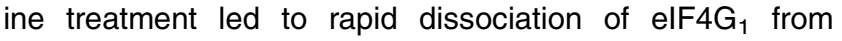
elF4E, which became almost maximal at $2 \mathrm{~h}$ of treatment (the ratio of $4 \mathrm{E} / 4 \mathrm{G}_{1}$ from staurosporine cells was 10 -fold less than in the DMSO control). This is consistent with the increased level of 4E-BP1 associated with elF4E in response to staurosporine treatment (a ratio of 0.8 in the staurosporine treated cells compared to 0.1 in the DMSO control), which in turn matches the decreased levels of phosphorylation of 4E-BP1 observed at these times (Figure 2D). Rapamycin, used as a positive control, also caused rapid dissociation of elF4F complexes. These data show that staurosporine causes dephosphorylation of two targets of the mTOR signalling pathway. However, BIM does not have this effect, indicating that this is not a consequence of inhibition of PKC signalling.

\section{Staurosporine does not inhibit mTOR associated kinase activity in vitro}

To establish whether staurosporine inhibited mTOR directly, FLAG-tagged mTOR was overexpressed in human embryonic kidney 293 (HEK 293) cells and the cells were starved of serum overnight. Cells were then stimulated with insulin for $60 \mathrm{~min}$, to activate mTOR-dependent signalling, and mTOR was immunoprecipitated using a monoclonal antiFLAG antibody. mTOR kinase activity was then measured in vitro against recombinant 4E-BP1 with varying concentrations of staurosporine (Figure 2F). The FKBP12/ rapamycin complex or wortmannin have each been previously shown to inhibit mTOR kinase activity in vitro. ${ }^{20,21}$ As expected, mTOR kinase activity was inhibited by pre-incubating the purified FLAG-tagged mTOR with either the FKBP12/rapamycin complex or $1 \mu \mathrm{M}$ Wortmannin prior to the kinase assay as observed by a major loss in the incorporation of ${ }^{32} \mathrm{P}$-label into recombinant 4E-BP1. However, none of the concentrations of staurosporine used (as high as $1 \mu \mathrm{M}$ ) inhibited the mTOR-associated kinase activity when compared to the control where no inhibitor was added. This indicates that staurosporine does not cause the dephosphorylation of downstream components of mTOR signalling through a direct inhibition of mTOR itself. 
A

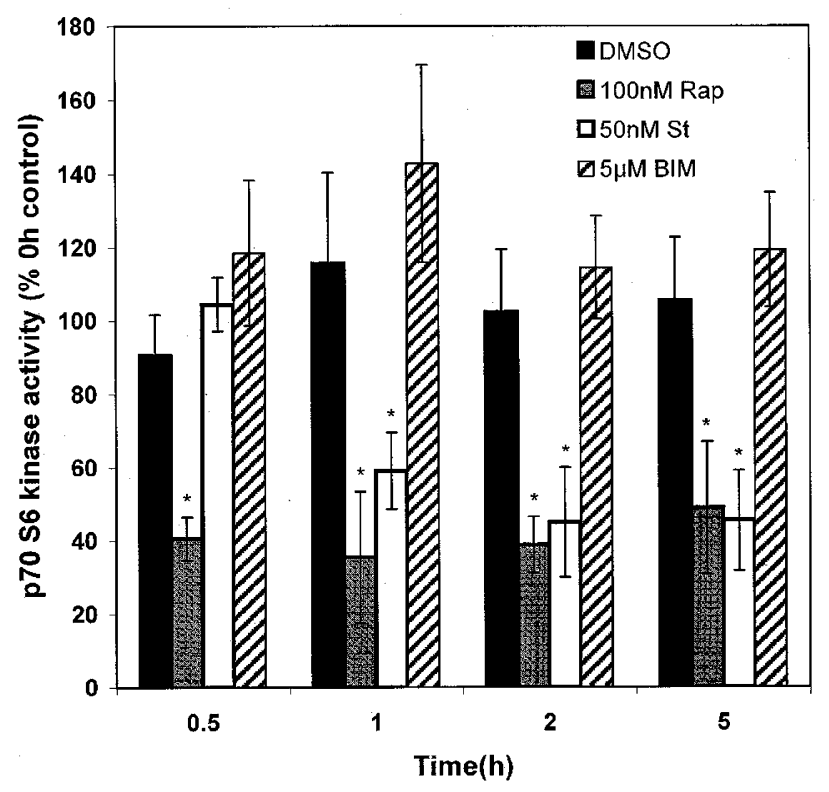

B

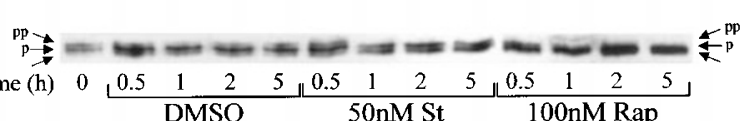

C

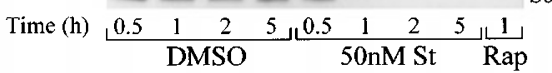

D

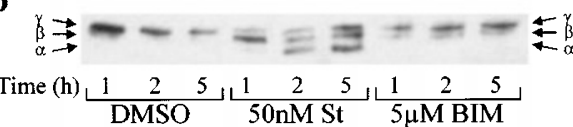

$\mathbf{E}$

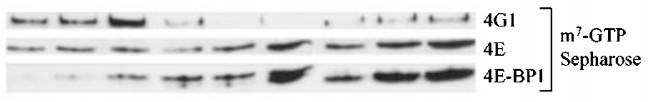

$\begin{array}{llllllllll}\text { Ratio 4E/4GI } & 1 & 1 & 1.3 & 0.6 & 0.1 & 0 & 0.2 & 0.2 & 0.3\end{array}$

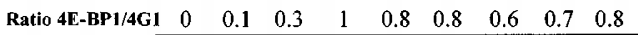

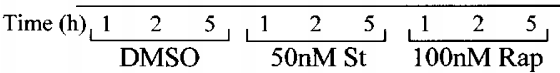

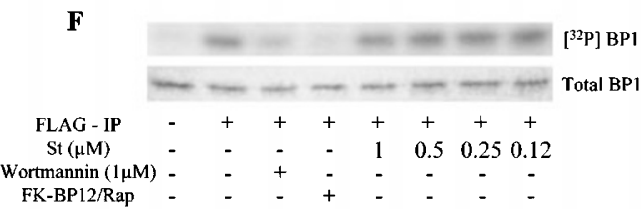

Figure 2 Staurosporine causes inhibition of downstream components of mTOR before the induction of apoptosis. (A) Swiss 3T3 cells were treated as indicated (with DMSO, staurosporine ( $50 \mathrm{nM} \mathrm{St}$ ), rapamycin (100 nM Rap) or bisindolylmaleimide ( $5 \mu \mathrm{M}$ BIM)). p70 S6 kinase assays were carried out on the cell extracts $(150 \mu \mathrm{g})$, made as described in the Materials and Methods $\left({ }^{*}=P<0.005\right.$ versus $0 \mathrm{~h}$ control before treatment, data show \pm S.D. $\left.(n=3)\right) .(B)$ Western blot analysis was carried out on the extracts made as indicated to determine the phosphorylation state of p70 S6 kinase. The arrows indicate differently phosphorylated species of p70 S6 kinase where the top arrow

\section{Staurosporine inhibits insulin-stimulated signalling through mTOR}

To study whether staurosporine inhibited acute insulinstimulated signalling through mTOR, serum starved Swiss ЗТ3 cells were pre-treated with DMSO, staurosporine or rapamycin prior to the addition of insulin for a short time course. To monitor acute insulin-stimulated signalling through mTOR the phosphorylation status of downstream targets of mTOR; 4E-BP1 (Figure 3A), p70 S6 kinase (Figure 3B) and ribosomal protein $\mathrm{S} 6$ (Figure $3 \mathrm{C}$ ) was assessed. After $15 \mathrm{~min}$ insulin evoked a strong phosphorylation of 4E-BP1, with a marked increase in the proportion of the protein migrating most highly as the phosphorylated $\gamma$-species (Figure 3A). Treatments with staurosporine or rapamycin treatments, however, prevented this upward shift in migration. Staurosporine and rapamycin also each reduced the basal phosphorylation status of p70 S6 kinase (compared to the DMSO treated lanes) so that the main species migrated as the lowest, least phosphorylated form (Figure 3B). Staurosporine also largely blocked the ability of insulin to induce phosphorylation of p70 S6 kinase relative to the DMSO control, although not to quite the same extent as rapamycin, which completely blocked this effect. Staurosporine and rapamycin each blocked the phosphorylation of the ribosomal S6 protein which was observed upon insulin stimulation (Figure $3 \mathrm{C}$ ). These three parallel experiments strongly suggest that staurosporine does indeed inhibit mTORdependent signalling, i.e., through a component other than mTOR itself. This effect, however, appears less potent than that of rapamycin, given that insulin still evoked a partial bandshift to the higher phosphorylated species of p70 S6 kinase upon insulin stimulation in the presence of staurosporine (Figure 3B).

\begin{abstract}
(labelled pp) indicates the slowest migrating most phosphorylated isoform (more active), while the lowest arrow depicts the fastest migrating lowest phosphorylated isoform (less active). (C) Western blot analysis using an antibody that specifically recognises the phosphorylated form of ribosomal protein S6 (S6-P) was carried out on the extracts made, as indicated. (D) The samples, where indicated, were subjected to SDS-PAGE and Western blot analysis to assess the phosphorylation state of 4E-BP1. The $\alpha, \beta$ and $\gamma$ isoforms of 4E-BP1 are indicated by the arrows. The $\gamma$ species represents the most highly phosphorylated form of $4 \mathrm{E}-\mathrm{BP} 1$ and the $\alpha$ species the least phosphorylated form of $4 \mathrm{E}-\mathrm{BP} 1$. (E) Cell extracts ( $200 \mu \mathrm{g}$ protein) from Swiss 3T3 cells treated as indicated were subjected to affinity chromatography on $\mathrm{m}^{7}$ GTP-Sepharose as described in Materials and Methods. The relative amounts of elF4G $14 \mathrm{G} 1)$, elF4E (4E) and 4E-BP1 were compared by Western blot analysis followed by densitometry (NIH Image v. 1.61). (F) In vitro mTOR kinase activity. FLAG-tagged mTOR was immunoprecipated using the FLAG antibody coupled to protein G-Sepharose where indicated (FLAG-IP); otherwise protein G-Sepharose beads were used alone. Associated mTOR kinase activity was measured in the presence of either staurosporine (St) at the indicated concentration, Wortmannin, or FKBP12/rapamycin complex (FKBP12/Rap) as indicated. The kinase assay using 4E-BP1 as a substrate was carried out as described in the Materials and Methods and the incorporation of ${ }^{32} \mathrm{P}$-label into 4E-BP1 ([ $\left.\left.{ }^{32} \mathrm{P}\right] \mathrm{BP} 1\right)$ was visualised by autoradiography. To verify that the levels of $4 \mathrm{E}-\mathrm{BP} 1$ used in each assay were the same, the total levels of 4E-BP1 were determined by staining the gel with Coomassie brilliant blue (Total BP1). A photograph of the stained gel is shown
\end{abstract}



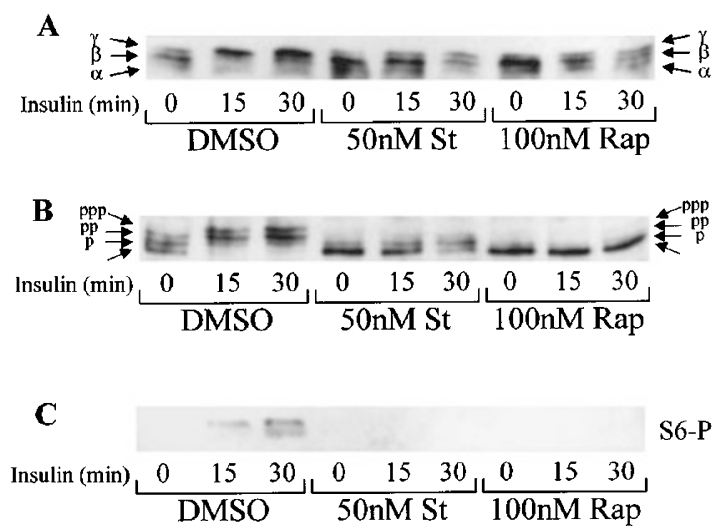

S6-P

Figure 3 Staurosporine inhibits insulin-induced signalling through mTOR. (A) Swiss 3T3 cells that were serum starved overnight and then pre-treated for $30 \mathrm{~min}$ as indicated (with DMSO, staurosporine $(50 \mathrm{nM} \mathrm{St})$ or rapamycin $(100 \mathrm{nM}$ Rap)), followed by stimulation with insulin $(100 \mathrm{nM})$ for the times stated. Cells were extracted and the samples were subjected to SDS-PAGE and Western blot analysis to assess the phosphorylation state of 4E-BP1, as previously described in Figure 2D. (B) Samples of the same extracts were analysed (as before, Figure $2 \mathrm{~B}$ ) to determine the phosphorylation state of p70 $\mathrm{S} 6$ kinase. The arrows indicate the various phosphorylated forms of p70 S6 kinase where the top arrow (labelled ppp) indicates the slowest migrating most phosphorylated isoform. The lower arrows (labelled $p p, p$ and unlabelled) indicate the forms of p70 S6 kinase in order of decreased phosphorylation and the unlabelled arrow represents the least phosphorylated species. (C) Western blot analysis using an antibody that specifically recognises the phosphorylated form of ribosomal protein S6 (S6-P) was carried out on the extracts

\section{Rapamycin delays staurosporine-induced caspase activation}

mTOR-linked signalling is inhibited by staurosporine before the induction of apoptosis and raises the question of what role this inhibition plays during the course of apoptosis. Rapamycin delayed staurosporine-induced cell death, observed by a decrease in the caspase- 3 activity from cells treated with staurosporine in the presence of rapamycin when compared to cells only treated with staurosporine (Figure 4). Cells that were pre-treated with rapamycin showed a twofold reduction in caspase-3 activity at $20 \mathrm{~h}$ when compared with cells treated with staurosporine alone. This result would suggest that the direct inhibition of mTOR by rapamycin, especially when prolonged, can inhibit cellular commitment to apoptosis.

\section{Staurosporine treatment causes increased elF2 $\alpha$ phosphorylation linked to the inhibition of PKC}

A further translation factor which plays an important role in controlling protein synthesis under a wide variety of conditions is elF2. Phosphorylation of its $\alpha$-subunit (elF2 $\alpha$ ) leads to the inhibition of translation initiation as the phosphorylated form acts as a competitive inhibitor of elF2B. ${ }^{22}$ In many cell types relatively low levels of elF $2 \alpha$ phosphorylation can exert a marked inhibition on translation as cellular levels of elF2 exceed those of elF2B. ${ }^{23}$ The level of phosphorylation of elF2 $\alpha$ was assessed by Western blot analysis with an antibody that recognises elF2 $\alpha$ when phosphorylated at

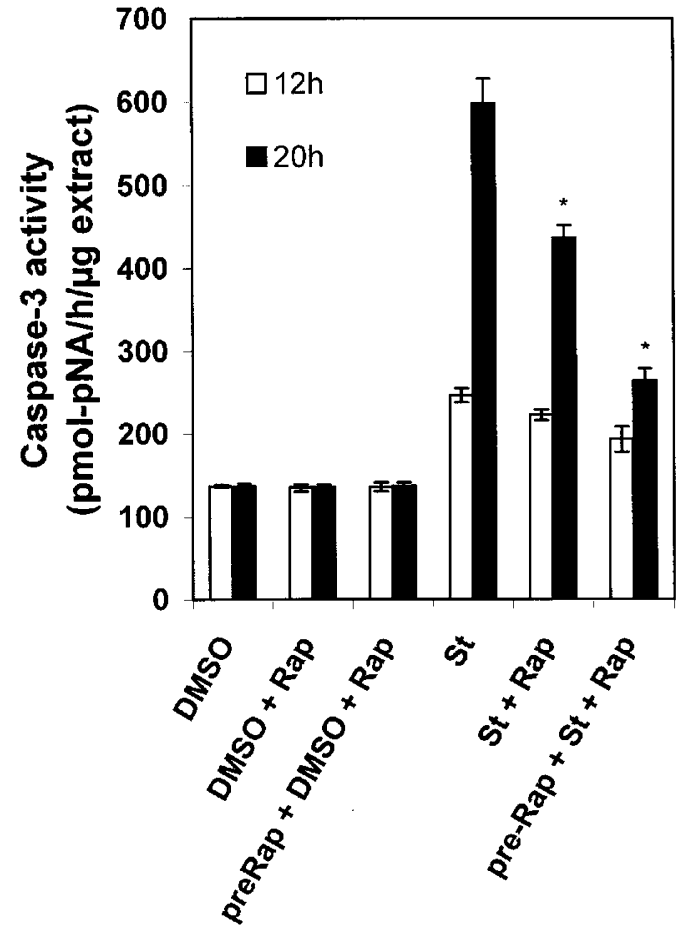

Figure 4 Rapamycin treatment delays caspase-3 activation in staurosporinetreated cells. Swiss 3 T3 cells were treated with DMSO or staurosporine (St, $50 \mathrm{nM}$ ) in the presence or absence of rapamycin (Rap, $100 \mathrm{nM}$ ) or with rapamycin alone for 12 and $24 \mathrm{~h}$. Where stated, the cells were pre-treated with rapamycin (preRap, $100 \mathrm{nM}$ ) for $12 \mathrm{~h}$ before the addition of a second dose of rapamycin ( $+/-$ staurosporine). The cells were analyzed for caspase-3 activity as described in Materials and Methods, $\left({ }^{*}=P<0.005\right.$ versus appropriate DMSO or staurosporine $12 \mathrm{~h}$ control, where appropriate, data show \pm S.D. $(n=3))$

Ser51 (P-elF2 $\alpha$-lgG). As a (loading) control, an antibody that recognises elF $2 \alpha$ irrespective of its state of phosphorylation (elF2 $\alpha-\lg G$ ) was used. The ratio of phosphorylated elF2 $\alpha$ to the elF2 $\alpha$ loading control was determined by densitometry. This analysis was performed for early times of staurosporine treatment, up to $5 \mathrm{~h}$ (Figure $5 \mathrm{~A}$ ) and also at later times, up to $18 \mathrm{~h}$ (Figure 5B). Staurosporine-treated cells show an increase in elF2 $\alpha$ phosphorylation when compared to the DMSO negative control at times as early as $1 \mathrm{~h}$ (Figure $5 \mathrm{~A}$ ) that became maximal at $5 \mathrm{~h}$ (Figure $5 \mathrm{~B}$ ). Staurosporine and BIM each caused similar increases in elF2 $\alpha$ phosphorylation when compared to the ratio of phosphorylated elF2 $\alpha$ from the DMSO controls that was negligible. The levels of phosphorylation were significantly less than those caused by arsenite, a stress which causes marked increases in elF2 $\alpha$ phosphorylation in several cell types (see, e.g. ${ }^{22}$ ).

\section{Staurosporine inhibits protein synthesis independently of caspase activation}

Several laboratories have reported an inhibition of total protein synthesis caused by cytotoxic chemicals that induce apoptosis. ${ }^{14,15}$ We have previously shown that inhibition of total protein synthesis in Swiss 3T3 cells by etoposide, a 


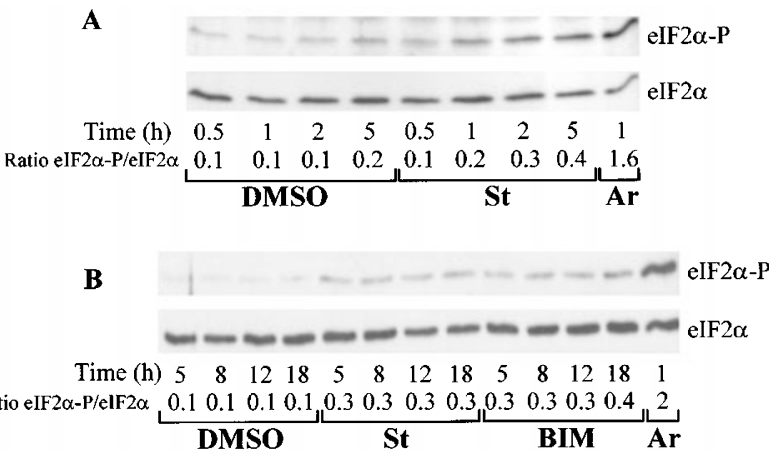

Figure 5 Staurosporine and bisindolylmaleimide each induce phosphorylation of elF2 $\alpha$. Swiss 3 T3 cells were treated as indicated (DMSO, $50 \mathrm{nM}$ staurosporine (St), $200 \mu \mathrm{M}$ arsenite ( $\mathrm{Ar}$ ) or $5 \mu \mathrm{M}$ bisindolylmaleimide (BIM)) for early times up to $5 \mathrm{~h}(\mathbf{A})$ and later times up to $18 \mathrm{~h}(\mathbf{B})$. Samples of cell lysate (15 $\mu$ g protein) were subjected to SDS - PAGE and Western blot analysis with an antibody that recognises elF2 $\alpha$ when phosphorylated at Ser51 (labelled 'elF2 $\alpha$-P') or an antibody that detects total elF2 $\alpha$ (labelled 'elF2 $\alpha$ '). The ratio of elF2 $\alpha$-P to elF2 $\alpha$ was compared by densitometry (NIH Image v. 1.61)

DNA-damaging agent, precedes the onset of apoptosis and may have an important role during the decision phase of apoptosis. ${ }^{14}$ It was therefore of interest to establish whether staurosporine inhibited total protein synthesis before Swiss 3T3 cells began to undergo apoptosis. Swiss 3T3 cells were treated with staurosporine in the presence or absence of ZVAD.FMK and total protein synthesis was measured by measuring the incorporation of $\left[{ }^{35} \mathrm{~S}\right]$-methionine into protein (Figure 6). Substantial inhibition of translation was observed after $8 \mathrm{~h}$ of staurosporine treatment, i.e., well before the onset of apoptosis, as judged by an increase in caspase- 3 activity (Figure 1A) and the appearance of the cleavage product of 4E-BP1 (Figure 1B), both of which occurred at $12 \mathrm{~h}$. Furthermore, Z-VAD.FMK did not prevent this inhibition of translation, as expected, since this inhibition precedes caspase activation, indicating that this is independent of caspase activation. BIM only exerted a smaller inhibitory effect on overall translation than staurosporine at $8 \mathrm{~h}$ or $12 \mathrm{~h}$, indicating again that the effect of staurosporine is not primarily due to inhibition of PKC signalling. At longer times of treatment with staurosporine, BIM did exert a more marked effect on protein synthesis rates suggesting that long term inhibition of PKC may affect the protein synthesis machinery.

\section{Discussion}

The present findings show for the first time that staurosporine treatment of mammalian cells causes inactivation of factors and protein kinases important for the control of mRNA translation. The phosphorylation of elF2 $\alpha$ and the dephosphorylation of 4E-BP1, p70 S6 kinase and the ribosomal protein S6 occurred before the Swiss 3T3 cells had committed themselves to undergo apoptosis, i.e., prior to caspase activation and the cleavage of 4E-BP1. This inactivation of factors linked to mTOR is not due to the direct inhibition of mTOR by staurosporine, as demonstrated by the data in Figure 2F. Neither is staurosporine likely to inhibit mTOR signalling through the direct inhibition of PKC because BIM,

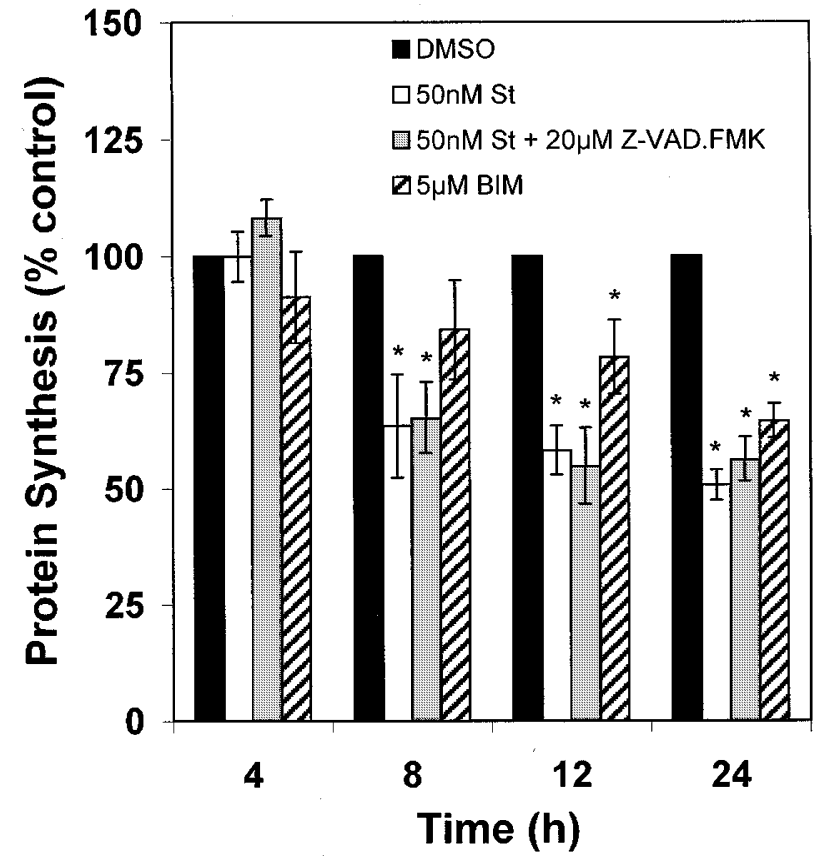

Figure 6 Staurosporine inhibits total protein synthesis, partly due to inhibition of PKC, before the onset of apoptosis. Swiss 3T3 cells were treated with DMSO, staurosporine in the presence or absence of Z-VAD.FMK, or bisindolylmaleimide for the times indicated. The cells were incubated with $\left[{ }^{35} \mathrm{~S}\right]$-methionine for a further $20 \mathrm{~min}$, after the indicated time, before harvesting. The incorporation of radiolabel into intracellular protein was measured as described in the Materials and Methods. All samples were equilibrated for protein levels and standardised against the DMSO control (set at $100 \%)$ at each time point $\left({ }^{*}=P<0.005\right.$ versus appropriate DMSO control, data show \pm S.D. $(n=3))$

another agent which inhibits PKC, did not affect the levels of phosphorylation of these downstream components of mTOR signalling (Figure 2A and D). To examine whether mTOR activity itself was inhibited during these treatments the endogenous mTOR was immunoprecipitated from Swiss 3T3 cells and its activity measured in vitro. There was no significant difference in the incorporation of ${ }^{32} \mathrm{P}$-label into the substrate, 4E-BP1, between the samples from serum starved, insulin stimulated or staurosporine treated cells (data not shown). We felt that this assay may not accurately reflect the mTOR (associated) activity within these cells as the two extreme controls (serum starved and insulin treated) were not obviously different. Staurosporine did, however, inhibit the acute insulin-induced mTOR signalling observed in the repression of the phosphorylation of 4E-BP1 (Figure $3 \mathrm{~A}$ ), p70 S6 kinase (Figure $3 \mathrm{~B}$ ) and ribosomal S6 protein (Figure $3 C)$. The effects caused by staurosporine are therefore likely to arise from the inhibition of other kinases in the mTOR pathway that are upstream of both 4E-BP1 and p70 S6 kinase.

The dephosphorylation of the elF4E binding protein 4EBP1 induced by staurosporine led to increased binding of 4E-BP1 to elF4E and decreased levels of the translation initiation factor complex elF4F. Since this complex plays an important role in the initiation of cap-dependent translation, staurosporine is expected to impair this process. elF4F 
complex formation is considered to be particularly important for the translation of highly structured mRNAs (e.g. those for transcription factors, such as c-myc and c-fos, reviewed in. ${ }^{24}$ ) The study by Novoa and Carrasco ${ }^{25}$ suggests that elF4F complexes are primarily needed for de novo initiation rather than reinitiation onto the same mRNA. Staurosporine also caused both the dephosphorylation and inactivation of p70 S6 kinase as well as a decrease in the phosphorylation of its substrate, ribosomal protein S6. p70 S6 kinase is implicated primarily in the regulation of specific sets of mRNAs by promoting the translation of $5^{\prime}$-TOP mRNAs which encode elongation factors and ribosomal proteins. ${ }^{3,4,26}$ Over an extended time period, inhibition of p70 S6 kinase is therefore expected to decrease the numbers of ribosomes present within the cell due to the impaired synthesis of ribosomal proteins. Therefore, the inhibition of both elF4F complex formation and p70 S6 kinase activity would not have a great effect on total protein synthesis in the short term but would however inhibit protein sythesis in the long term when new mRNAs are synthesised and ribosome numbers are reduced. The idea that inhibition of mTOR contributes to the shut-off of protein synthesis is consistent with the present data and with the fact that rapamycin, which inhibits mTOR directly, significantly inhibits protein synthesis at longer time points $\left(12-18 \mathrm{~h}^{14,27}\right)$.

We found that staurosporine markedly inhibited overall protein synthesis independently of caspase activation. We have previously reported that treatment of Swiss 3T3 cells with rapamycin only significantly inhibited total protein synthesis at times of $12 \mathrm{~h}$ or longer. ${ }^{14}$ It is therefore unlikely that the inhibition of total protein synthesis by staurosporine by $8 \mathrm{~h}$ is due entirely to the inhibition of mTOR signalling. Indeed, the onset of this inhibition on protein synthesis by staurosporine was slower than the inhibition of p70 S6 kinase or elF4F formation. It is likely that the inhibition of these downstream targets of mTOR contributes to the inhibition of general protein synthesis at the longer time points, i.e., by reducing ribosomal numbers and reduced translation initiation of newly-made mRNAs. The timing of elF2 $\alpha$ phosphoylation also does not correlate with the inhibition of protein synthesis observed with both staurosporine and BIM treatment. Both treatments caused a similar degree of elF2 $\alpha$ phosphorylation after $5 \mathrm{~h}$, but whereas staurosporine caused significant inhibition of protein synthesis at this time, BIM did not. This suggests that the inhibition observed with staurosporine cannot be accounted for by the levels of elF2 $\alpha$ phosphorylation. Therefore, the inhibition of protein synthesis by staurosporine must also involve another as-yet-unidentified mechanism.

Our earlier studies have shown that DNA-damaging agents bring about inhibition of mTOR signalling ${ }^{14}$ and Morley and co-workers have shown that apoptosis induced by cycloheximide was also accompanied by increased association of 4E-BP1 with elF4E. ${ }^{28}$ Taken together with our present data, it is clear that a number of cell treatments which induce apoptosis cause dephosphorylation of $4 \mathrm{E}$ BP1 and other targets of mTOR signalling. Inactivation of the same targets of mTOR signalling in response to other treatments which induce apoptosis suggests that their modulation may be a common feature of the processes leading to cellular commitment to apoptosis prior to the execution of cell death. However, at least in the cells we have studied (Swiss 3T3 and HEK293), rapamycin itself does not induce apoptosis. Thus inhibition of mTOR is not in itself sufficient to induce apoptosis, although rapamycin has been reported to enhance the sensitivity of cells to certain other pro-apoptotic agents. ${ }^{29,30}$ In Swiss 3T3 cells rapamycin however, delayed staurosporine-induced caspase activation. Rapamycin-treatment of Swiss 3T3 cells would provide a more sustained and possibly more severe inhibition of mTOR signalling than would occur by treating with staurosporine alone, as indicated by the data in Figure 3B. This suggests that the inhibition of mTOR may play a crucial role during the decision phase of apoptosis by delaying caspase activation. It is interesting to note that rapamycin, ${ }^{31}$ DNA-damaging agents ${ }^{20}$ and staurosporine ${ }^{32}$ have all been reported to cause a $G_{1}$ cell cycle arrest in a variety of cell types. It is therefore possible that both DNAdamaging agents and staurosporine elicit this $G_{1}$ cell cycle arrest through an inhibition of mTOR and this arrest may be a common event to delay cell cycle progression during treatments that cause apoptosis. This may explain why rapamycin delayed the execution of apoptosis induced by staurosporine as rapamycin is likely to synergise with staurosporine to delay cell cycle progression. In contrast to these cytotoxic agents which induce cell death by causing cellular stress, receptor-mediated apoptosis leads to the commitment of apoptosis through direct activation of this caspase cascade. ${ }^{33}$ Such receptor-mediated apoptosis has been shown to cause an inhibition of mRNA translation that was blocked by Z-VAD.FMK showing that it was dependent on caspase activation. ${ }^{34}$ This finding indicates that inhibition of translation occurred during the stages of apoptosis when cells were already committed to die and, therefore, different from our data.

This study, taken with earlier reports ${ }^{14,28}$, therefore suggests that inhibition of mTOR signalling is a common response of mammalian cells during the 'decision' phase of chemical-induced apoptosis. Potent apoptotic agents that include DNA-damaging agents, cycloheximide treatment and now staurosporine have all been shown to inhibit translation regulators linked to mTOR before the execution of apoptosis. Our data also show that staurosporine inhibits protein synthesis. This involves, at least in part, the phosphorylation or activity of multiple translational regulators including elF2 $\alpha$, elF4F, p70 S6 kinase and the ribosomal protein $S 6$. Such effects on the translation machinery would likely regulate the translation of a subset of pro-survival and pro-apoptotic mRNAs thus contributing to the balance of events which determine cellular commitment to apoptosis (reviewed $\mathrm{in}^{35}$ ), but before caspases are activated.

\section{Materials and Methods}

\section{Materials}

Staurosporine was obtained from Sigma while bisindolylmaleimide-I was purchased from Calbiochem. All other reagents were purchased as previously described. ${ }^{14}$ 


\section{Cell culture and cell treatments}

Swiss 3T3 cells, kindly provided by Dr BA Spruce (University of Dundee), were maintained as previously described. ${ }^{14}$ The cells were transferred to fresh Dulbecco's modified Eagle's medium (DMEM) supplemented with $10 \%(\mathrm{v} / \mathrm{v})$ foetal calf serum $5 \mathrm{~h}$ before treatment, unless stated otherwise, with staurosporine, rapamycin or bisindolylmaleimide dissolved in dimethyl sulphoxide (DMSO) to a fina concentration of $0.1 \%(\mathrm{v} / \mathrm{v})$ DMSO where stated in the figure legends. Control cells received the same concentration of DMSO. Transient transfections were performed as described by Hall-Jackson et al. ${ }^{36}$ with the following modifications: air was bubbled into the $2 \times$ Hepes Buffered Saline solution by using a drawn-out glass pasteur pipette upon the slow addition of the $\mathrm{CaCl}_{2} / \mathrm{DNA}$ mix.

\section{In vitro kinase assays}

mTOR kinase activity was measured on FLAG-tagged mTOR immunoprecipitated from $500 \mu \mathrm{g}$ of cell lysates prepared from HEK293 cells transiently transfected with pcDNA3.1mTOR-FLAG using a monoclonal anti-FLAG antibody from Sigma coupled to protein G-Sepharose. Preparations of the cell lysates and assay was carried out as previously described ${ }^{21}$ with the following modifications: the FLAG-tagged mTOR coupled to the protein G-Sepharose were preincubated with $0.2 \mathrm{mM}$ ATP for $20 \mathrm{~min}$ at $30^{\circ} \mathrm{C}$ and then incubated with the inhibitors or FKBP12/rapamycin complex for 20 min on ice before the reaction was initiated by addition of $1 \mu \mathrm{g}$ of $4 \mathrm{E}-\mathrm{BP} 1$ and $0.2 \mu \mathrm{Ci}\left[\gamma^{32} \mathrm{P}\right] \mathrm{ATP}$. The FKBP12/rapamycin complex was generated by incubating $30 \mathrm{mM}$ rapamycin with FKBP12 for $5 \mathrm{~min}$ in the dark at $20^{\circ} \mathrm{C}$. To measure p70 S6 kinase activity the p70 S6 kinase was immunoprecipitated using anti-(p70 S6 kinase) antibodies and its activity measured against a peptide substrate based on the 32 amino acid sequence of the $\mathrm{C}$-terminus of $\mathrm{S} 6$, as previously described. ${ }^{14}$

\section{Analysis of translation factors and assays for both protein synthesis and apoptosis}

Affinity chromatography on $\mathrm{m}^{7} \mathrm{GTP}$-Sepharose was used to isolate elF4E and its associated proteins, e.g., elF4G ${ }_{1}$ and 4E-BP1, from $250 \mu \mathrm{g}$ (protein) of Swiss $3 \mathrm{~T} 3$ cell lysate. The amounts of both elF4G ${ }_{1}$ and $4 \mathrm{E}-$ BP1 bound to elF4E were assessed by running the purified samples on a $12.5 \%$ polyacrylamide gel followed by transfer to Immobilon membranes and Western blot analysis as described earlier. ${ }^{37,38}$ The mobility shift gel assays were performed by using a 10/0.1\% acrylamide/bis-acrylamide gel for the analysis of p70 S6 kinase and a $13.5 / 0.36 \%$ acrylamide/bisacrylamide gel for resolving 4E-BP1. Assays for determining rates of protein synthesis using ${ }^{35} \mathrm{~S}$-methionine as label were carried out as previously reported ${ }^{14}$ while caspase activation was determined by using the CaspACE ${ }^{\mathrm{TM}}$ System Colorimetric Assay Kit from Promega according to the manufacturer's instructions.

\section{Acknowledgements}

We would like to thank Dr. BA Spruce for the cell-lines and helpful discussions, Dr. G Krause (Wayne State University, MI, USA) and Prof. RM Denton (University of Bristol) for supplying antibodies. We would also like to thank Dr. P Shepherd (University College, London) for providing the FLAG-tagged mTOR construct, Dr. P Scott (University of Glasgow) for supplying the FKBP12 recombinant protein, Dr. DR Alessi (University of Dundee) for providing the ribosomal protein S6 phospho-specific antibody and Dr. TP Herbert (University of Dundee) for critical reading of the manuscript. This work was supported by the Wellcome Trust through the award of a Prize Studentship to AR Tee.

\section{References}

1. Rhoads RE (1999) Signal transduction pathways that regulate eukaryotic protein synthesis. J. Biol. Chem. 274: 30337-30340

2. Kleijn M, Scheper GC, Voorma HO and Thomas AAM (1998) Regulation of translation initiation factors by signal transduction. Eur. J. Biochem. 253: 531 544

3. Fumagalli $S$ and Thomas $G$ (2000) S6 phosphorylation and signal transduction. In Translational control of gene expression, Sonenberg N, Hershey JWB and Mathews MB, eds (Cold Spring Harbor, NY: Cold Spring Harbor Laboratory Press) pp.695-717

4. Meyuhas $O$ and Hornstein E (2000) Translational control of TOP mRNAs. In Translational control of gene expression, Sonenberg N, Hershey JWB and Mathews MB, eds (Cold Spring Harbor, NY: Cold Spring Harbor Laboratory Press) pp. 671-693

5. Lawrence JC and Abraham RT (1997) PHAS/4E-BPs as regulators of mRNA translation and cell proliferation. Trends Biochem. Sci. 22: 345-349

6. Gingras A-C, Raught B and Sonenberg N (1999) elF4 translation factors: effectors of mRNA recruitment to ribosomes and regulators of translation. Annu. Rev. Biochem. 68: 913-963

7. Clemens MJ (1996) Protein kinases that phosphorylate elF2 and elF2B, and their role in eukaryotic cell translational control. In Translational control of gene expression, Sonenberg N, Hershey JWB and Mathews MB, eds (Cold Spring Harbor, NY: Cold Spring Harbor Laboratory Press) pp. 139-172

8. Balachandran S, Kim CN, Yeh W-C, Mak TW, Bhalla K and Barber GN (1998) Activation of the dsRNA-dependent protein kinase, PKR, induces apoptosis through FADD-mediated death signaling. EMBO J. 17: 6888-6902

9. Donze O, Dostie J and Sonenberg N (1999) Regulatable expression of the interferon-induced double-stranded RNA dependent protein kinase PKR induces apoptosis and fas receptor expression. Virology 256: $322-329$

10. Gil J, Alcami J and Esteban M (1999) Induction of apoptosis by double-strandedRNA-dependent protein kinase (PKR) involves the alpha subunit of eukaryotic translation initiation factor 2 and NF-kappaB. Mol. Cell. Biol. 19: 4653-4663

11. Takizawa T, Tatematsu $C$ and Nakanishi $Y$ (1999) Double-stranded RNAactivated protein kinase (PKR) fused to green fluorescent protein induces apoptosis of human embryonic kidney cells: possible role in the Fas signaling pathway. J. Biochem. (Tokyo). 125: 391-398

12. Yeung MC, Liu J and Lau AS (1996) An essential role for the interferon-inducible, double-stranded RNA-activated protein kinase PKR in the tumor necrosis factorinduced apoptosis in U937 cells. Proc. Natl. Acad. Sci. USA 93: 12451-12455

13. Hengartner MO (2000) The biochemistry of apoptosis. Nature 407: 770-776

14. Tee AR and Proud CG (2000) DNA damage causes inactivation of translational regulators linked to $m$ TOR signalling. Oncogene 15: 3021-3031

15. Clemens MJ, Bushell M and Morley SJ (1998) Degradation of eukaryotic polypeptide chain initiation factor (elF) $4 \mathrm{G}$ in response to induction of apoptosis in human lymphoma cell lines. Oncogene 17: 2921-2931

16. Haraguchi M, Torii S, Matsuzawa SI, Xie Z, Kitada S, Krajewski S, Yoshida H, Mak TW and Reed JC (2000) Apoptotic protease activating factor 1 (Apaf-1)independent cell death suppression by Bcl-2. J. Exp. Med. 191: 1709-1720

17. Rocha S, Soengas MS, Lowe SW, Glanzmann C, Fabbro D, Winterhalter K, Bodis S and Pruschy M (2000) Protein kinase C inhibitor and irradiation-induced apoptosis: relevance of the cytochrome c-mediated caspase- 9 death pathway. Cell Growth Differ. 11: $491-499$

18. Davies SP, Reddy H, Caivano M and Cohen P (2000) Specificity and mechanism of action of some commonly used protein kinase inhibitors. Biochem. J.351: 95105

19. Han Z, Pantazis P, Lange TS, Wyche JH and Hendrickson EA (2000) The staurosporine analog, Ro-31-8220, induces apoptosis independently of its ability to inhibit protein kinase C. Cell Death Differ. 7: 521-530

20. Huang TS, Kuo ML, Shew JY, Chou YW and Yang WK (1996) Distinct p53mediated G1/S checkpoint responses in two NIH3T3 subclone cells following treatment with DNA-damaging agents. Oncogene 13: 625-632

21. Brunn GJ, Williams J, Sabers C, Weiderrecht G, Lawrence JC and Abraham RT (1996) Direct inhibition of the signalling functions of the mammalian target of rapamycin by the phosphoinositide 3-kinase inhibitors, wortmannin and LY294002. EMBO J. 15: 5256-5267

22. Brostrom CO and Brostrom MA (1998) Regulation of translational initiation during cellular responses to stress. Prog. Nucleic Acid Res. Mol. Biol. 58: 79125 
23. Oldfield S, Jones BL, Tanton D and Proud CG (1994) Use of monoclonal antibodies to study the structure and function of eukaryotic protein synthesis initiation factor elF2B. Eur. J. Biochem. 221: 399-410

24. Clemens MJ and Bommer U-A (1999) Translational control: the cancer connection. Int. J. Biochem. Cell Biol. 31: 1-23

25. Novoa land Carrasco L (1999) Cleavage of eukaryotic translation initiation factor $4 \mathrm{G}$ by exogenously added hybrid proteins containing poliovirus $2 \mathrm{Apro}$ in $\mathrm{HeLa}$ cells: effects on gene expression. Mol. Cell. Biol. 19: 2445-2454

26. Meyuhas O, Avni D and Shama S (1996) Translational control of ribosomal protein mRNAs in eukaryotes. In Translational control of gene expression, Sonenberg N, Hershey JWB and Mathews MB, eds (Cold Spring Harbor, NY. Cold Spring Harbor Laboratory Press) pp.363-388

27. Beretta L, Gingras AC, Svitkin YV, Hall MN and Sonenberg N (1996) Rapamycin blocks the phosphorylation of 4E-BP1 and inhibits cap-dependent initiation of translation. EMBO J. 15: 658-664

28. Bushell M, Wood W, Clemens MJ and Morley SJ (2000) Changes in integrity and association of eukaryotic protein synthesis initiation factors during apoptosis. Eur. J. Biochem. 267: 1083-1091

29. Ishizuka T, Sakata N, Johnson GL, Gelfand EW and Terada N (1997) Rapamycin potentiates dexamethasone-induced apoptosis and inhibits JNK activity in lymphoblastoid cells. Biochem. Biophys. Res. Commun. 230: 386-391

30. Shi J, Frankel A, Radvanyi LG, Penn LZ, Miller RG and Mills GB (1995) Rapamycin enhances apoptosis and increases sensitivity to cisplatin in vitro. Cancer Res. 55: 1982-1988

31. Brown EJ, Albers MW, Shin TB, Ichikawa K, Keith CT, Lane WS and Schreiber SL (1994) A mammalian protein targeted by G1-arresting rapamycin-receptor complex. Nature 369: $756-758$
32. Zong ZP, Fujikawa-Yamamoto K, Li AL, Yamaguchi N, Chang YG, Murakami M Odashima $S$ and Ishikawa $Y$ (1999) Both low and high concentrations of staurosporine induce $\mathrm{G} 1$ arrest through down-regulation of cyclin $\mathrm{E}$ and cdk2 expression. Cell Struct. Funct. 24: 457-463

33. Sun X-M, MacFarlane M, Zhuang J, Wolf BB, Green DR and Cohen GM (1999) Distinct caspase cascades are initiated in receptor-mediated and chemicalinduced apoptosis. J. Biol. Chem. 274: 5053-5060

34. Morley SJ, McKendrick L and Bushell M (1998) Cleavage of translation initiation factor 4G (elF4G) during antiFas IgM-induced apoptosis does not require signalling through the p38 mitogen-activated protein (MAP) kinase. FEBS Lett. 438: $41-48$

35. Holcik M, Sonenberg N and Korneluk RG (2000) Internal ribosome initiation of translation and the control of cell death. Trends in Genetics 16: 469-473

36. Hall-Jackson CA, Cross DA, Morrice N and Smythe C (1999) ATR is a caffeinesensitive, DNA-activated protein kinase with a substrate specificity distinct from DNA-PK. Oncogene 18: 6707-6713

37. Wang X, Campbell LE, Miller CM and Proud CG (1998) Amino acid availability regulates $\mathrm{p} 70 \mathrm{~S} 6 \mathrm{kinase}$ and multiple translation factors. Biochem. J. 334: $261-$ 267

38. Campbell LE, Wang X and Proud CG (1999) Nutrients differentially modulate multiple translation factors and their control by insulin. Biochem. J. 344: 433441 